\title{
ANIMAL SPIRITS, TECHNOLOGY SHOCKS AND THE BUSINESS CYCLE
}

\author{
Mark WEDER*
}

July 1, 1997

\begin{abstract}
In this paper a two-sector growth model allowing indeterminacy to occur at relatively mild degrees of increasing returns is developed. It is shown that these economies of scale need only be present in one sector of the economy (investment). This feature of the model, therefore, builds on evidence that was recently reported by Basu and Fernald (1996). The model is also able to solve some puzzles of business cycle research which standard Real Business Cycle models have not been able to. The introduction of animal spirits generates a low negative contemporaneous correlation of hours and productivity as well as a procyclical investment share. The model can account for the observed variability of hours worked.
\end{abstract}

${ }^{*}$ Keywords: Sunspots, technology shocks, economic fluctuations, Dunlop-Tarshispuzzle.

Journal of Economic Literature Classification: E00, E32.

Humboldt University Berlin, Department of Economics, Spandauer Str. 1, 10178 Berlin, Germany, weder@wiwi.hu-berlin.de.

I am indebted to Michael Burda for his guidance. I would like to thank Jess Benhabib, Dalia Marin, Ellen McGrattan, Harald Uhlig, Thomas Sargent, Rolf Tschernig and participants of the 1996 Summer School of the European Economic Association for valuable comments. All remaining errors are mine. 


\section{Introduction}

The last few years have witnessed a revival of business cycle models in which beliefs of agents (or animal spirits) have played a leading role in explaining economic fluctuations. ${ }^{1}$ Most of these models involve strong economy-wide increasing returns to scale in order for sunspot equilibria to exist. In a recent paper, however, Basu and Fernald (1996) present evidence that returns to scale are far from evenly distributed across the U.S. economy. In particular,they report that scale economies are present mainly in the domain of durable goods production. In the nondurable goods sector of the U.S. economy evidence of increasing returns to scale cannot be found.

The innovation of this paper is to demonstrate that Basu and Fernalds's (1996) findings can be used within a two-sectoral optimal growth model to generate non-uniqueness of rational expectations equilibria. It is assumed that each of the two sectors produces a list of intermediate consumption goods or investment goods respectively. The number of these goods is fixed and each intermediate good is produced by one industry each. I consider Cournot competition in each industry. Endogenous entry and exit of firms in each product's industry results in a variable mark up. Indeterminacy arises at returns to scale of around 1.15 in the investment sector alone. This indeterminacy can then be exploited so that animal spirits can be introduced as a driving variable in order to generate cyclical behavior of the model as in Farmer (1993).

Although the debate on business cycles was revived as a result of the new literature on self-fulfilling expectations, it is indisputable that recent developments have failed to produce a widely accepted paradigm as of today. The principal problem of the mentioned work is the dependency on degrees of scale economies and market power that are not suggested by (most) empirical studies. The exception is Benhabib and Farmer (1996) who seem to have found an escape out of this dilemma. They are able to show that by working with a two-sector optimal growth model the extent of increasing returns that is needed to obtain indeterminacy can be reduced significantly. ${ }^{2}$ The principal difference between their work and mine is that these authors do not

\footnotetext{
${ }^{1}$ See for example Farmer (1993), Farmer and Guo (1994), and Schmitt-Grohe (1995).

${ }^{2}$ The abnormal behavior of two-sector growth models was already examined in the sixties (for example Shell, 1967).
} 
consider any asymmetry of scale economies of the sort reported by Basu and Fernald (1996). A further distinction is that they do not use oligopoly as I do.

Technology shocks will not be dismissed as a source of economic fluctuations in this work altogether. I will entertain the idea of a coexistence (and coimportance) of both shocks in the economy as in Farmer and Guo (1995) and others. ${ }^{3}$ They have found that demand and supply shocks account for about the same magnitude in explaining business cycles in the U.S. post-war period. Another reason for considering two simultaneous shocks was given by McGrattan (1994), Baxter and King (1991) and others. According to McGrattan, the major problems of the standard Real Business Cycle model are the predictions of variability of hours and the impossibility to account for the Dunlop-Tarshis puzzle. ${ }^{4}$ These deficits can be overcome once additional disturbances (to technology shocks) are introduced. McGrattan (1994) assumes stochastic taxation as well as shocks to government expenditures. Baxter and King (1991) obtain a similar result when preference shocks are introduced into the Real Business Cycle model. Both of these works are able to generate a low correlation of hours and productivity. ${ }^{5}$ The intention of this work is to demonstrate that these and other complications of Real Business Cycle models can also be solved within a general equilibrium model in which both animal spirits and technology shocks are the forcing variables.

The paper proceeds as follows: Section 2 presents the model. The economy's steady state and its dynamics around it will be derived in section 3. In section 4 the model is calibrated. This is followed by two exercises; the first will establish parameter constellations at which indeterminacy is possible and the second will compute model statistics to assess the model's business cycle properties (sections 5 and 6 ). Section 7 concludes the paper.

\footnotetext{
${ }^{3}$ See for example Gerlach and Smets (1995).

${ }^{4}$ The Dunlop-Tarshis puzzle implies that real wages and labor input move acyclical to each other.

${ }^{5}$ Christiano and Eichenbaum (1992) consider stochastic government expenditures plus technology shocks.
} 


\section{The model}

The economic model developed is a two-sector extension of a baseline Real Business Cycle model as in, for example, King, Plosser and Rebelo (1988). ${ }^{6}$ It is assumed that the markets for investment goods and consumption goods are characterized by oligopoly. ${ }^{7}$

\subsection{The household}

I will assume that the economy consists of a representative household. The household supplies labor and capital services to the firms on competitive markets. I assume that the representative agent has expected lifetime utility

$$
E\left[\sum_{t=0}^{\infty} \beta^{t} U\left(C_{t}, l_{t}\right) \mid \mathcal{I}_{t}\right]
$$

where $U($.$) is instantaneous utility, C_{t}$ is a consumption index, $l_{t}$ leisure time, $\beta$ the discount factor and $\mathcal{I}_{t}$ the set of information available at $t$. Consumption of the households is defined by a CES-aggregator over all differentiated goods available (normalized to unity):

$$
C_{t}=\left(\int_{0}^{1} C_{c, t}^{v} d c\right)^{1 / v}
$$

The number of consumption goods is constant. Consumption is a function of the consumption level of an assembled variety of the differentiated goods indexed by $c$. Each of these goods enters the aggregator symmetrically. For $v<1$, the goods are imperfect substitutes. Analogously to the definition of the consumption bundle, an aggregator for the investment good, $I_{t}$, is defined. Again it is a CES-function of the purchases of the differentiated products:

$$
I_{t}=\left(\int_{0}^{1} I_{i, t}^{\theta} d i\right)^{1 / \theta} .
$$

\footnotetext{
${ }^{6}$ See also Christiano and Fisher (1995).

${ }^{7}$ Another work which includes oligopoly in the Real Business Cycle framework is Gali (1995).
} 
The number of investment goods is constant. The period-by-period budget constraint of the household is given by

$$
\int_{0}^{1} p_{c, c, t} C_{c, t} d c+\int_{0}^{1} p_{i, i, t} I_{i, t} d i=w_{t} L_{t}+q_{t} K_{t}+\Pi_{t}
$$

Here $p_{c, c, t}\left(p_{i, i, t}\right)$ is the price of the consumption (investment) good $c(i)$. Both prices are taken as given for the households. $w_{t}$ is the nominal wage. Furthermore, the household receives profit income from all existing firms $\Pi_{t}$. Households own the stock of capital $K_{t}$ and rent it out to the firms at the rental price $q_{t}$. All factor prices and profit income are taken as given for the households. Households are endowed with one unit of time per period which they can either use for leisure or work $L_{t}$ :

$$
1=L_{t}+l_{t}
$$

The following specific functional form for periodic utility is assumed:

$$
U\left(C_{t}, L_{t}\right)=\log C_{t}+\frac{B}{1+\chi} l_{t}^{1+\chi}, \quad \text { with } \chi \leq 0 .
$$

$B$ is a constant. The consumer's capital holdings evolve as

$$
K_{t+1}=(1-\delta) K_{t}+I_{t},
$$

where $\delta$ is the rate of depreciation. The household maximizes (1) subject to (4), (5) and (7). As is well known for this class of models, maximization can be conducted as a two step procedure. The current-periodic household expenditure functional of consumption goods subject to $C_{t}$ is given by

$$
\mathbf{E}\left(\mathbf{p}_{c, c, t}, C_{t}\right)=C_{t}\left(\int_{0}^{1} p_{c, c, t}^{\frac{v}{1-v}} d c\right)^{\frac{1-v}{v}}
$$

where $\mathbf{p}_{c, c, t}$ is a function of the consumption goods' prices. By applying Shephard's Lemma in the first step, the conditional demand can be derived as

$$
C_{c, t}=\left(\frac{p_{c, c, t}}{p_{c, t}}\right)^{\frac{1}{v-1}} C_{t}
$$


which has a constant price elasticity. Here

$$
p_{c, t} \equiv\left(\int_{0}^{1} p_{c, c, t}^{\frac{v}{v-1}} d c\right)^{\frac{v-1}{v}}
$$

is the exact price index for the consumption goods. The conditional demand becomes

$$
I_{i, t}=\left(\frac{p_{i, i, t}}{p_{i, t}}\right)^{\frac{1}{\theta-1}} I_{t}
$$

and

$$
p_{i, t} \equiv\left(\int_{0}^{1} p_{i, i, t}^{\frac{\theta}{\theta-1}} d i\right)^{\frac{\theta-1}{\theta}}
$$

Given the conditional demands, I am able to derive the intertemporal optimality condition for the household. In symmetric equilibrium, the only case to be considered in this paper, the household buys the same amount of every product: $C_{c, t}=C_{t}$ (and $I_{i, t}=I_{t}$ ). The prices of all goods equal. Finally, I use the price of the consumption goods in equilibrium as the numeraire and, without loss of generality, normalize it to unity. The budget constraint transforms into

$$
C_{t}+p_{t} I_{t}=w_{t} L_{t}+q_{t} K_{t}+\Pi_{t}
$$

$p_{t}$ can be interpreted as the relative price of investment goods in symmetric equilibrium.

The second step of the household's optimization program consists of computing the optimal path of spending and working. Each household chooses a sequence $\left\{C_{t}, L_{t}, K_{t+1}\right\}_{t=0}^{\infty}$ subject to $K_{0}$ and to the distribution of technology innovations (see below). The first order conditions can be written as 8

$$
\begin{gathered}
C_{t}^{-1}-\lambda_{t}=0 \\
B\left(1-L_{t}\right)^{\chi}-\lambda_{t} w_{t}=0
\end{gathered}
$$

\footnotetext{
${ }^{8}$ Here $\lambda_{t}$ is the current value Lagrange multiplier associated with the household's resource constraint.
} 


$$
\beta E\left[\lambda_{t+1}\left(q_{t+1}+(1-\delta) p_{t+1}\right) \mid \mathcal{I}_{t}\right]-\lambda_{t} p_{t}=0,
$$

plus the household's period-by-period budget constraint

$$
w_{t} L_{t}+q_{t} K_{t}+\Pi_{t}-C_{t}-p_{t} I_{t}=0
$$

and the transversality condition

$$
\lim _{s \rightarrow \infty} E\left[\beta^{t+s-1} \lambda_{t+s-1} K_{t+s} \mid \mathcal{I}_{t}\right]=0 .
$$

(14) and (15) describe the household's consumption-leisure trade off and (16) is the standard intertemporal optimality condition.

\subsection{The firms}

One significant modification of conventional Real Business Cycle modelling is considered: I assume that consumption and investment goods are produced in two distinct sectors. Households can move their labor and capital services freely and without costs between the two sectors. ${ }^{9}$ It is also assumed that product markets are oligopolistic. Factor prices are given for the individual firm and household.

\subsection{The consumption goods sector}

The part of the economy that produces consumption goods consists of subsectors, each producing a differentiated product. The measure of subsectors is normalized to one. ${ }^{10}$ There are $N_{c, t}$ firms supplying their single good $j$ every period $t$. Each firm $j$ supplies its product in sector (market) $c$ under the assumption of Cournot competition. $N_{c, t}$ must not necessarily be constant. Costless endogenous entry and exit of firms will be allowed.

Firm's $j$ output $Y_{c, j, t}$ is related to capital input $K_{c, j, t}$ and labor input $L_{c, j, t}$ according to the production function

$$
Y_{c, j, t}=C_{c, j, t}=Z_{t}\left(K_{c, j, t}^{\alpha} L_{c, j, t}^{1-\alpha}\right)^{\gamma}-\phi
$$

\footnotetext{
${ }^{9} \mathrm{~A}$ possible and realistic extension of the model would be the introduction of limited mobility of labor and capital.

${ }^{10}$ Basically both sectors of the economy are the same in structure. Therefore, only the sector that is discussed first is described in detail.
} 
where $\phi$ is overhead costs. $Z_{t}$ is the state of technology which evolves as

$$
\log Z_{t+1}=\rho \log Z_{t}+z_{t+1}, \quad 0<\rho<1 .
$$

Units have been chosen to make the conditional mean $E\left[Z_{t}\right]=1$. The sequence $\left\{z_{t}\right\}$ is a normally distributed white noise process with zero mean and constant variance $\sigma_{z}^{2}$. Given the assumption on the form of competition, the firm's program can be written in the specific Cournot form

$$
\max \Pi_{c, j, t}=\left(\frac{C_{c,-j, t}+C_{c, j, t}}{C_{t}}\right)^{v-1} p_{c, t} C_{c, j, t}-w_{t} L_{c, j, t}-q_{t} K_{c, j, t}
$$

subject to its production function (19). $p_{c, j, t}$ is the price of the firm's $j$ good (in market $c$ ) and $C_{c,-j, t}$ is the supply of all other firms in sector $c$ which is taken as given for every firm $j$. The cost function of firm $j$ is given by

$$
\mathrm{C}\left(w_{t}, q_{t}, C_{c, j, t}\right)=A q_{t}^{\alpha} w_{t}^{1-\alpha}\left(\frac{C_{c, j, t}+\phi}{Z_{t}}\right)^{\frac{1}{\gamma}},
$$

where the constant $A$ is defined as $A \equiv\left(\frac{\alpha}{1-\alpha}\right)^{1-\alpha}+\left(\frac{\alpha}{1-\alpha}\right)^{-\alpha}$. Each firm $j$ maximizes its profits $(20)$ given the quantity supplied by others. Optimality requires that

$$
\begin{gathered}
(v-1) p_{c, j, t}\left(C_{c,-j, t}+C_{c, j, t}\right)^{-1} C_{c, j, t}+p_{c, j, t} \\
=\frac{A}{\gamma Z_{t}} q_{t}^{\alpha} w_{t}^{1-\alpha}\left(\frac{C_{c, j, t}+\phi}{Z_{t}}\right)^{\frac{1}{\gamma}-1}
\end{gathered}
$$

holds. (22) equalizes marginal revenues and marginal costs. Marginal costs are decreasing (increasing) for $\gamma>1(\gamma<1)$. At every period in time the number of active firms is implicitly determined by the zero profit condition

$$
p_{c, j, t} C_{c, j, t}=A q_{t}^{\alpha} w_{t}^{1-\alpha}\left(\frac{C_{c, j, t}+\phi}{Z_{t}}\right)^{\frac{1}{\gamma}} .
$$

Inserting the optimal pricing rule into the zero profit condition yields

$$
p_{c, j, t} C_{c, j, t}=\gamma\left((v-1)\left(C_{c,-j, t}+C_{c, j, t}\right)^{-1} p_{c, j, t} C_{c, j, t}+p_{c, j, t}\right)\left(C_{c, j, t}+\phi\right) .
$$

In symmetric equilibrium $N_{c, t} C_{c, j, t}=C_{c, t}=C_{t}, N_{c, t}=N_{t}$ and $p_{c, j, t}=p_{c, t}=1$ hold, where the last equality follows from the normalization that was already 
made in section 2. Equation (24) has the aggregate correspondence in symmetric equilibrium of ${ }^{11}$

$$
C_{t}=\gamma\left(\frac{v-1}{N_{t}}+1\right) Z_{t} K_{c, t}^{\alpha \gamma} L_{c, t}^{(1-\alpha) \gamma} N_{t}^{1-\gamma} .
$$

The term $1+\frac{v-1}{N_{t}}$ is the inverse of the markup in the consumption goods sector. Note that the markup is decreasing in $v$ which implies that a low specialization of the input goods translates into a low degree of market power. The markup is also decreasing in the number of firms. That is, the model predicts a countercyclical pattern of the markup. This is supported by empirical evidence summarized by Rotemberg and Woodford (1991). ${ }^{12}$

Combining the optimal markup rule (22) with the conditional demand for labor, it is possible to derive the (equilibrium) wage rate as

$$
w_{t}=(1-\alpha) \gamma\left(1+\frac{v-1}{N_{c, t}}\right) Z_{t}\left(K_{c, j, t}^{\alpha} L_{c, j, t}^{1-\alpha}\right)^{\gamma} L_{c, j, t}^{-1} .
$$

Accordingly, the rental rate of capital is given by the term

$$
q_{t}=\alpha \gamma\left(1+\frac{v-1}{N_{c, t}}\right) Z_{t}\left(K_{c, j, t}^{\alpha} L_{c, j, t}^{1-\alpha}\right)^{\gamma} K_{c, j, t}^{-1} .
$$

Note that this simple aggregation of the conditional demands does not yet yield the actual rental prices. These demands must be combined with the equilibrium value for $N_{c, t}$, as given by the zero profit condition.

\subsection{The investment goods sector}

There are $M_{i, t}$ firms supplying their respective investment good $j$ in sector (market) $i$ every period $t{ }^{13}$ The market structure and the production

\footnotetext{
${ }^{11}$ Equation (25) can be rewritten as

$$
C_{t}=\frac{\gamma \phi\left(v-1+N_{t}\right)}{1-\gamma\left(\frac{v-1}{N_{t}}+1\right)}
$$

which states, for example, that for a given number of firms $N_{t}$, a rise of overhead costs must be met by a rise in sales of consumption goods $C_{t}$ (otherwise the number of firms must decrease). Also, a fall in $v$ and a fall in $N_{t}$ increases the production of consumption goods.

${ }^{12}$ See also Burda (1985).

${ }^{13}$ Again the letter $j$ denotes the individual firm.
} 
technology in the investment goods sector are essentially the same as in the consumption goods sector. Each firm $j$ supplies its product in sector $j$ under the assumption of Cournot competition. It operates under the technology

$$
Y_{i, j, t}=I_{i, j, t}=Z_{t}\left(K_{i, j, t}^{\alpha} L_{i, j, t}^{1-\alpha}\right)^{\eta}-\Gamma \text {. }
$$

Here $I_{i, j, t}$ is the amount of output to be sold by the $j t h$ firm in sector $i . K_{i, j, t}$ and $L_{i, j, t}$ are capital and labor input of firm $j$ at $t$. $\Gamma$ is overhead costs when operating the firm. Each firm $j$ solves

$$
\max \Pi_{i, j, t}=\left(\frac{I_{i,-j, t}+I_{i, j, t}}{I_{t}}\right)^{\theta-1} p_{i, t} I_{i, j, t}-\mathbf{C}\left(w_{t}, q_{t}, I_{i, j, t}\right)
$$

where $I_{i,-j, t}$ is the supply of all other firms in sector $i$. The sequence of deriving a firm's optimal program in the investment sector is the same as in the consumption sector. Again the number of equilibrium firms is determined by free entry and exit. In symmetric equilibrium, the zero profit condition is given by

$$
I_{t}=\eta\left(\frac{\theta-1}{M_{t}}+1\right) Z_{t} K_{i, t}^{\alpha \eta} L_{i, t}^{(1-\alpha) \eta} M_{t}^{1-\eta}
$$

The optimal inverse factor demands are implicitly determined (in symmetric equilibrium) by

$$
w_{t}=(1-\alpha) \eta p_{t}\left(1+\frac{\theta-1}{M_{t}}\right) Z_{t}\left(K_{i, t}^{\alpha} L_{j, t}^{1-\alpha}\right)^{\eta} M_{t}^{1-\eta} L_{i, t}^{-1}
$$

and

$$
q_{t}=\alpha \eta p_{t}\left(1+\frac{\theta-1}{M_{t}}\right) Z_{t}\left(K_{i, t}^{\alpha} L_{i, t}^{1-\alpha}\right)^{\eta} M_{t}^{1-\eta} K_{i, t}^{-1}
$$

\subsection{Factor markets in symmetric equilibrium}

By combining (14), (15), (25) and (26), labor input in the consumption goods sector is given as

$$
(1-\alpha) L_{c, t}^{-1}=B\left(1-L_{t}\right)^{\chi}
$$


As long as $\chi \neq 0, L_{c, t}$ and $L_{t}$ move in opposite directions, labor input in the consumption sector is countercyclical. This is an unrealistic feature of any two-sector optimal growth model with endogenous labor supply.

The continua of firms in the two sectors rent factor services from the same market. Combining the factor market clearing conditions (26), (27), (31) and (32) yields an equalization of factor intensities in the form

$$
\frac{K_{c, t}}{L_{c, t}}=\frac{K_{i, t}}{L_{i, t}}=\frac{K_{t}}{L_{t}}
$$

Finally I define overall sales $Y_{t}$ as the measure of output in the economy. ${ }^{14}$

Sales are given by

$$
Y_{t}=C_{t}+p_{t} I_{t}
$$

\section{The equilibrium dynamics}

This section describes the steady state and the dynamics of the model economy.

\subsection{The steady state of the economy}

The steady state is given by the following list of equations (36 to 40). Omitting the time index refers to steady state variables.

$$
\begin{gathered}
\beta^{-1} p=q+(1-\delta) p \\
\delta=I / K \\
\frac{\phi N}{C}=\frac{N-\gamma(v-1+N)}{\gamma(v-1+N)} \\
\frac{\Gamma M}{I}=\frac{M-\eta(\theta-1+M)}{\eta(\theta-1+M)}
\end{gathered}
$$

\footnotetext{
${ }^{14}$ In this model I measure aggregate economic activity by sales and not by overall production which would include the overhead. However, it can be shown that the general results are not affected by the particular choice of an output measure.
} 
Equations (36) and (37) are generally found in Real Business Cycle models. (38) and (39) can be interpreted as follows: both equations are the steady state versions of the zero-profit condition for each of the two sectors in the economy. The left hand side is the ratio of overhead to output in each sector. (38) can be interpreted as follows: assume a rise in $v$, that is, a lower market power for each firm in the consumption sector market, implying that the left hand side of (38) must decrease. For a given overhead and $C$, the steady state number of firms falls. The same result occurs for an increase in $\theta$ and $\gamma(\eta)$. For a given overhead and $C$, the steady state number of firms falls. Similar results occur for an increase in $\theta$ or $\gamma(\eta)$.

\subsection{The solution mechanism}

The following section describes the dynamics of the economy near its steady state. Since the Second Welfare Theorem does not apply because of the existing market power, the dynamics cannot be derived by means of the social planner problem. I therefore use the solution method described by King, Plosser and Rebelo (1988), which involves approximating the necessary and sufficient first order conditions into a first order linear system. ${ }^{15}$

Define the vector $\hat{\Omega}_{t}$ according to ${ }^{16}$

$$
\hat{\Omega}_{t}=\left[\hat{C}_{t}, \hat{Y}_{t}, \hat{I}_{t}, \hat{w}_{t}, \hat{q}_{t}, \hat{L}_{t}, \hat{L}_{c, t}, \hat{L}_{i, t}, \hat{K}_{c, t}, \hat{K}_{i, t}, \hat{N}_{t}, \hat{M}_{t}\right]^{\prime} .
$$

The vector of controls is related to the relative price, to the capital stock and to the technology (the vector of states) as

$$
J_{1} \hat{\Omega}_{t}=J_{2}\left[\begin{array}{c}
\hat{p}_{t} \\
\hat{K}_{t} \\
\hat{Z}_{t}
\end{array}\right]
$$

where $J_{1}$ and $J_{2}$ are $12 \times 12$ and $12 \times 3$ matrices respectively. The loglinearized versions of the Euler equation, the budget constraint as well as the technology process relate variations in $\hat{p}, \hat{K}$ and $\hat{Z}$ to changes in $\hat{\Omega}_{t}$ :

$$
J_{3}(L)\left[\begin{array}{c}
E\left[\hat{p}_{t+1} \mid \mathcal{I}_{t}\right] \\
\hat{K}_{t+1} \\
E\left[\hat{Z}_{t+1} \mid \mathcal{I}_{t}\right]
\end{array}\right]=J_{4}(L) \hat{\Omega}_{t+1}
$$

\footnotetext{
${ }^{15}$ See also Woodford (1986) and Uhlig (1995) for justifications of this method.

${ }^{16} \hat{U}_{t}$ denotes the percentage deviation of the variable $U_{t}$ from its steady state value $U$ at $t$.
} 
where the $J_{j}(L)$ s are matrix polynomials in the lag operator $L$ at most power of one. The last two equations can be combined to yield

$$
\left[\begin{array}{c}
E\left[\hat{p}_{t+1} \mid \mathcal{I}_{t}\right] \\
\hat{K}_{t+1} \\
\hat{Z}_{t+1}
\end{array}\right]=J\left[\begin{array}{c}
\hat{p}_{t} \\
\hat{K}_{t} \\
\hat{Z}_{t}
\end{array}\right]+\left[\begin{array}{c}
0 \\
0 \\
z_{t+1}
\end{array}\right]
$$

where $J$ is $3 \times 3$. A three-dynamical system describes the economy's dynamics. The eigenvalues of $J$ must be evaluated at the steady state. The system contains: one predetermined variable, the stock of capital, $\hat{K}_{t}$, one endogenous (nonpredetermined) variable, $\hat{p}_{t}$, and one exogenous (nonpredetermined) variable, $\hat{Z}_{t}$. Thus, if all eigenvalues of $J$ are inside the unit circle, the rational expectations equilibrium is non-unique. This will be analyzed in the following section. The calibration method will be applied to check if indeterminacy has realistic relevance.

\section{Calibration}

Parameter value determination will follow in the Real Business Cycle tradition. Steady state values of the model will be matched with estimates of average growth rates and great ratios. First a baseline model structure will be defined. Without setting fixed values for all variables, the regions of realistic calibrations will be shown.

To calibrate the model as close as possible to established Real Business Cycle theory, I will set parameters as proposed in existing studies. Quarterly $\delta$ is equal to 0.025 and $\alpha$ (the capital share) is set at 0.36 , which is standard in Real Business Cycle models (see for example Hansen, 1985).

Basu and Fernald (1995) report estimates for increasing returns from 1.00 to 1.26. However, their preferred point estimate is 1.03. In their work, the regression was restricted by assuming that returns to scale are the same over the economy. Basu and Fernald (1996) show that economies of scale are largely heterogenous across the economy, however. For durable goods manufacturing, they report significant increasing returns with a point estimate of 1.36 (their Table 3). ${ }^{17}$ For the production of nondurables, on the other hand,

\footnotetext{
${ }^{17}$ Depending on various estimation methods, the point estimate ranges from 1.07 (still significantly different from one) to 1.46 .
} 
(insignificant) diminishing returns are reported. Based on these results, it will be assumed that the consumption sector in the present model displays close to constant returns. This is a key assumption in this paper. These values restrict the region of the parameter space in which a realistic calibration can be undertaken.

The markups over marginal cost are given by

$$
\frac{1}{M C}=\frac{N}{v-1+N}
$$

for the consumption goods sector and by

$$
\frac{P}{M C}=\frac{M}{\theta-1+M}
$$

for the investment goods sector. The last two equations each possess one degree of freedom. For example, if I fix both the markup and $v$ in the consumption goods sector, the number of steady state firms $N$ is uniquely determined. The same holds for the investment goods sector.

Information does not exist in the empirical literature concerning the magnitude of the elasticity of substitution of investment and consumption goods in the aggregate. In models of monopolistic competition, the elasticity of substitution and the markup are interdependent since they are exactly inverse to each other. Consistent with the assumption of Cournot competition, the markup also depends on the number of incumbent firms. Basu and Fernald report markup margins from 1.00 to 1.26. Morrison (1990) reports the markup to be around 1.14. However, all of theses authors assume that the markup is homogenous over the economy. In light of the mentioned evidence in Basu and Fernald (1996), I will assume that the markup in the investment goods sector significantly exceeds the one in the consumption goods sector. Choosing a value for the steady state markup then determines the number of firms in the respective sector. I further assume that the inverse of $v(\theta)$ always equals the markup as a normalization.

I assign a value of $L=1 / 3$, implying that the representative agent spends on average one third of her time endowment working (see also Hansen, 1985). Note that in the case of $\chi=0$, the model's labor market corresponds to the Hansen (1985) and Rogerson (1987) indivisible labor market formulation. Labor supply becomes infinitely elastic. At $\chi=-1 / 2$, the model possesses 
a labor supply elasticity of 4 , which is the same as in the King, Plosser and Rebelo (1988) baseline Real Business Cycle model.

Next I will calibrate the ratio of consumption to output in the model economy. Kydland and Prescott (1990) report that total consumption expenditures amount to 80 percent of output net of government expenditures. If only expenditures on nondurables and services are considered, the ratio falls to 68 percent. I will fix the ratio of consumption to overall expenditures at 75 percent. This is done by adjusting the preference parameter $B$.

The rate of return in the model is given by

$$
r_{t+1}=\frac{q_{t+1}+(1-\delta) p_{t+1}}{p_{t}}-1
$$

which implies in steady state

$$
r=\frac{q}{p}-\delta=\frac{1}{\beta}-1
$$

where the last equality follows from (36). I set discount rate $\beta=0.99$. This assumption is standard in Real Business Cycle models. Using the last equation, the choice implies a rate of interest of four percent. $K_{i}$ can be computed from

$$
r=\frac{q}{p}-\delta=\alpha\left(\frac{\theta-1}{M}+1\right) K_{i}^{\alpha \eta-1} L_{i}^{(1-\alpha) \eta} M^{1-\eta}-\delta .
$$

$K_{c}$ is given by $K_{i} L_{c} / L_{i}$.

\section{$5 \quad$ Results}

In the first part of this section, I will evaluate the regions of parameter constellations in which indeterminacy can arise. Second moments are derived in the latter part of the section.

\section{$5.1 \quad$ Eigenvalues}

The occurrence of indeterminacy will be analyzed first. Indeterminacy is present in the model as long as both roots of the matrix $J$ are inside the unit 
circle. However, since the analytical solution of the matrix $J$ is muddled, a numerical procedure is considered here. Table 1 considers the parameters which are not changed in the analysis unless otherwise noted.

\begin{tabular}{|l|l|l|l|l|l|}
\hline \multicolumn{5}{|c|}{ Table 1: Parameters } \\
\hline \hline$L$ & $B$ & $\alpha$ & $v^{-1}$ & $\delta$ & $\beta$ \\
\hline $1 / 3$ & 2.55 & 0.36 & 1.03 & 0.025 & 0.99 \\
\hline
\end{tabular}

Considering the assumptions made, Table 1 implies that the markup in the consumption sector is equal to 1.03. This value is also the measure of increasing returns in this sector (see also the Appendix). ${ }^{18}$ A certain degree of scale economies is assumed to justify market power in the consumption goods sector. The choice for $B$ implies a consumption share of around 75 percent (the exact value depending on the remaining calibration).

The parameter space in which indeterminacy arises will be reported. Table 2 displays regions for indeterminacy for alternative values of scale economies in the investment goods sector. The labor market follows Hansen (1985), that is $\chi=0$. Marginal cost are constant in both sectors: $\gamma=\eta=1.00$.

\begin{tabular}{|l|l|l||l|}
\hline \multicolumn{4}{|c|}{ Table 2: Roots of Model } \\
\hline \hline$\theta^{-1}$ & Root 1 & Root 2 & stability \\
\hline \hline 1.10 & 1.108 & 0.926 & saddlepath stable \\
\hline 1.15 & 1.152 & 0.908 & saddlepath stable \\
\hline 1.20 & 1.412 & 0.850 & saddlepath stable \\
\hline 1.225 & $0.810+0.225 \mathrm{i}$ & $0.810-0.225 \mathrm{i}$ & stable \\
\hline 1.25 & $0.945+0.148 \mathrm{i}$ & $0.945-0.148 \mathrm{i}$ & stable \\
\hline 1.30 & $0.977+0.098 \mathrm{i}$ & $0.977-0.098 \mathrm{i}$ & stable \\
\hline 1.35 & $0.985+0.078 \mathrm{i}$ & $0.985-0.078 \mathrm{i}$ & stable \\
\hline 1.40 & $0.989+0.067 \mathrm{i}$ & $0.989-0.067 \mathrm{i}$ & stable \\
\hline 1.45 & $0.992+0.059 \mathrm{i}$ & $0.992-0.059 \mathrm{i}$ & stable \\
\hline
\end{tabular}

Table 2 shows that the present model does not require unrealistic scale

\footnotetext{
${ }^{18}$ It can be shown that the results reported in this paper are not dependent on the numerical choice of $v$. The basic features of the model carry over for different calibrations of $v$. In particular, $v \rightarrow 1$ does not pose any problems for the results that are reported in this paper.
} 
economies in order to produce indeterminacy. ${ }^{19}$ The model is indeterminate at increasing returns to scale in the investment goods sector of $\theta^{-1}=1.22$. Existing one sector animal spirits models which were summarized in SchmittGrohe (1995) require increasing returns in excess of 1.75 for variable markups and 2.31 for constant markups if the models were calibrated in the same way as in the present model. ${ }^{20}$ This result therefore indicates an improvement to previous work.

Table 3 repeats the analysis for nonconstant marginal costs. In particular, it is assumed that marginal costs are increasing: $\gamma=\eta=0.95$.

\begin{tabular}{|l|l|l||l|}
\hline \multicolumn{4}{|c|}{ Table 3: Roots of Model } \\
\hline \hline$\theta^{-1}$ & Root 1 & Root 2 & stability \\
\hline \hline 1.20 & 1.218 & 0.888 & saddlepath stable \\
\hline 1.24 & 0.716 & -0.189 & stable \\
\hline 1.25 & $0.845+0.216 \mathrm{i}$ & $0.845-0.216 \mathrm{i}$ & stable \\
\hline 1.30 & $0.969+0.114 \mathrm{i}$ & $0.969-0.114 \mathrm{i}$ & stable \\
\hline 1.35 & $0.983+0.086 \mathrm{i}$ & $0.983-0.086 \mathrm{i}$ & stable \\
\hline 1.40 & $0.988+0.071 \mathrm{i}$ & $0.988-0.071 \mathrm{i}$ & stable \\
\hline 1.45 & $0.991+0.062 \mathrm{i}$ & $0.991-0.062 \mathrm{i}$ & stable \\
\hline
\end{tabular}

This Table shows that indeterminacy is possible with upward sloping marginal costs schedules. The minimum required returns to scale is still not outside of what is considered realistic.

Table 4 considers diminishing marginal costs in the investment sector, $\eta=1.10($ and $\gamma=1.00)$.

\footnotetext{
${ }^{19}$ The matrix $J$ contains a third root which equals the parameter $\rho$. Since technology is assumed to be stationary, the third root is always inside the unit circle and is not reported in the Tables.

${ }^{20}$ In particular concerning the labor supply elasticity and the assumption on the value of $\alpha$.
} 


\begin{tabular}{|l|l|l||l|}
\hline \multicolumn{4}{|c|}{ Table 4: Roots of Model } \\
\hline \hline$\theta^{-1}$ & Root 1 & Root 2 & stability \\
\hline \hline 1.10 & 1.412 & 0.852 & saddlepath stable \\
\hline 1.14 & 0.700 & 0.028 & stable \\
\hline 1.15 & $0.811+0.225 \mathrm{i}$ & $0.811-0.225 \mathrm{i}$ & stable \\
\hline 1.20 & $0.963+0.125 \mathrm{i}$ & $0.963-0.125 \mathrm{i}$ & stable \\
\hline 1.25 & $0.980+0.091 \mathrm{i}$ & $0.980-0.091 \mathrm{i}$ & stable \\
\hline 1.30 & $0.986+0.075 \mathrm{i}$ & $0.986-0.075 \mathrm{i}$ & stable \\
\hline 1.35 & $0.989+0.065 \mathrm{i}$ & $0.989-0.065 \mathrm{i}$ & stable \\
\hline 1.40 & $0.992+0.058 \mathrm{i}$ & $0.992-0.058 \mathrm{i}$ & stable \\
\hline
\end{tabular}

Assuming decreasing marginal costs decreases the returns to scale that are needed to produce indeterminacy. They can be close to absent in the consumption sector and around 1.14 in the investment sector. These values are well within the reported scale economies in Basu and Fernald (1996).

Until now I have demonstrated the results in an indivisible labor environment only. In the following Table 5 it is assumed that $\chi=-1 / 2$, which is the same labor supply elasticity as in King, Plosser and Rebelo (1988). I assume constant marginal costs (and $B=2.1$ ).

\begin{tabular}{|l|l|l||l|}
\hline \multicolumn{4}{|c|}{ Table 5: Roots of Model } \\
\hline \hline$\theta^{-1}$ & Root 1 & Root 2 & stability \\
\hline \hline 1.20 & 1.119 & 0.924 & saddlepath stable \\
\hline 1.25 & 1.179 & 0.904 & saddlepath stable \\
\hline 1.30 & 2.607 & 0.820 & saddlepath stable \\
\hline 1.325 & $0.898+0.174 \mathrm{i}$ & $0.898-0.174 \mathrm{i}$ & stable \\
\hline 1.35 & $0.953+0.129 \mathrm{i}$ & $0.953-0.129 \mathrm{i}$ & stable \\
\hline 1.40 & $0.977+0.092 \mathrm{i}$ & $0.977-0.092 \mathrm{i}$ & stable \\
\hline 1.45 & $0.985+0.075 \mathrm{i}$ & $0.985-0.075 \mathrm{i}$ & stable \\
\hline
\end{tabular}

For lower labor supply elasticities, the scale economies needed are higher but still within the range that was reported in Basu and Fernald (1996). Moreover, the value of 1.32 is still lower than the point estimate of 1.36 in Basu and Fernald (1996). ${ }^{21}$ Therefore, my model does not rely on unrealistic labor supply elasticities in order to produce indeterminacy. It is also of

\footnotetext{
${ }^{21}$ Basu and Fernald (1996) report a wide array of estimates ranging from 1.10 to 1.50 depending on the particular method that is employed.
} 
interest that Basu (1995) notes that his results point to the case that observed scale economies do not come from decreasing marginal costs (as in Farmer and Guo, 1994, or Benhabib and Farmer, 1996), but rather from overhead. It is shown that decreasing marginal costs are not needed in the present model.

Overall the most significant aspect of my model is that it is able to yield an indeterminate solution for largely realistic parameter constellations. In light of recent critique on the animal spirits approach to business cycles, a criticism which centered on the implausible assumptions that were made on the degree of market imperfections, my model is able set out a structure that allows for the existence of indeterminacy at realistic measures. These increasing returns need only be present in the investment goods sector. Moreover, in the present economy increasing returns to scale are due to overhead costs, a feature which is also supported empirically. The model must still be evaluated to see how well it is able to replicate stylized business cycle facts, however. This will be carried out in the next section. Before doing so, I will give an economic reasoning for the result.

\subsection{The economic intuition behind the results}

The economic intuition for indeterminacy in my model can be formulated as follows: suppose agents expect (unrelated to any changes in economic fundamentals) that the (future) return to capital is going to be high. This will induce a shift of current resources towards investment goods. However, the expectations must be supported in the new equilibrium, namely at a higher return to capital. There are several ways to generate an increase in the rental rate at a higher level of economic activity. All of these features are present in my model. First of all, it is assumed that increasing returns are present in the economy. Second, labor moves freely across sectors. If the production of investment goods rises, labor is shifted into the investment goods sector and the return of a given stock of capital increases. Third, an increase in investment demand generates an inflow of firms. Since entry is costless, new firms enter each industry until profits are dissipated. A higher number of active firms $M_{t}$ implies that the mark up falls (see for example equation 40). The mark up is countercyclical in the I-sector. That is, for any given stock of capital, the labor input and the return to capital will be higher. If all of these features are combined, the return to capital can increase with economic activity if returns to scale are sufficiently but not unrealistically 
high.

\section{Business cycle properties}

\subsection{Population moments}

The model must still be judged on how good it can replicate the variability of the different aggregate macroeconomic time series behavior. In accordance with the Real Business Cycle approach, the generated model data will be compared with real data.

The following Table reports population moments for the U.S. economy. Log levels were detrended by using the Hodrick-Prescott filter. Table 6 reports the amplitudes of the fluctuations in aggregate variables in order to access their relative magnitudes. Comovements are reported as well.

\begin{tabular}{|c|c|c|c|c|}
\hline \multicolumn{5}{|c|}{$\begin{array}{l}\text { Selected U.S. Business Cycle Statistics, } \\
\text { Quarterly, 1954:I-1989:IV }\end{array}$} \\
\hline \multicolumn{2}{|c|}{ Variable } & \multirow{2}{*}{$\begin{array}{l}\begin{array}{l}\text { Relative } \\
\text { volatility }\end{array} \\
\sigma_{B} / \sigma_{A} \\
\end{array}$} & \multicolumn{2}{|c|}{$\begin{array}{l}\text { Dynamic correlation } \\
\text { of } A(t) \text { and } B(t-j) \\
\text { with } j=\end{array}$} \\
\hline$A$ & $B$ & & 0 & -1 \\
\hline$\overline{\mathrm{Y}}$ & - & 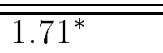 & 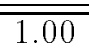 & $\overline{0.85}$ \\
\hline $\bar{Y}$ & $\mathrm{C} 1$ & 0.73 & 0.82 & 0.66 \\
\hline $\mathrm{Y}$ & $\mathrm{C} 2$ & 0.49 & 0.76 & 0.63 \\
\hline $\mathrm{Y}$ & $\mathrm{I}$ & 3.15 & 0.90 & 0.81 \\
\hline $\mathrm{Y}$ & L1 & 0.96 & 0.88 & 0.92 \\
\hline $\bar{Y}$ & L2 & 0.86 & 0.86 & 0.86 \\
\hline $\mathrm{Y}$ & $\mathrm{P} 1$ & 0.83 & 0.31 & -0.07 \\
\hline $\bar{Y}$ & $\overline{\mathrm{P} 2}$ & 0.88 & 0.51 & 0.21 \\
\hline $\bar{Y}$ & $\begin{array}{l}\text { IS } \\
\end{array}$ & 0.56 & 0.81 & 0.77 \\
\hline $\mathrm{Y}$ & - & $1.79^{*}$ & 1.00 & 0.86 \\
\hline $\mathrm{Y}$ & $\overline{\mathrm{L} 3}$ & 0.82 & 0.82 & 0.81 \\
\hline $\mathrm{Y}$ & P3 & 0.58 & 0.55 & 0.32 \\
\hline L3 & P3 & 0.70 & -0.03 & -0.07 \\
\hline$\overline{\mathrm{L} 4}$ & $\overline{\mathrm{P} 4}$ & 0.87 & -0.20 & n.a. \\
\hline
\end{tabular}

Deviations from Hodrick-Prescott filtered trend of input variables. Quarterly, 1954:I1989:IV. Variable definitions: Y=Real gross national output, C1=Consumption expenditures, $\mathrm{C} 2=$ Consumption expenditure on nondurables and services, I=Fixed investment, 
L1=Hours (establishment survey), L2=Hours (household survey), P1=Y/L1, P2=Y/L2, IS=investment expenditures share (fixed invesment). Results are taken from Kydland and Prescott (1990). The next four lines are taken from Christiano and Todd (1996) whose data set covers the 1947:I-1995:I period. L3=Hours worked by employed labor force, P3=Y/L3. L4 and P4 are from McGrattan (1994). * indicates that the number is the simple, not relative, standard deviation times 100 .

The well known business cycle fact is observed: consumption fluctuates less than output and investment displays a greater volatility than output. Labor input has cyclical variation which is almost as large as that of output. The right part of the table gives selected cross correlations of the variables. The column indexed by 0 denotes contemporaneous correlations. All variables peak with output. Furthermore, the correlation of productivity and hours is negative and close to zero. McGrattan (1994), who uses a different series for labor input, reports a contemporaneous correlation of productivity and hours of -0.20 (see also Baxter and King, 1991). This is the DunlopTarshis puzzle ${ }^{22}$ which states that real wages and labor input move acyclical to each other. ${ }^{23}$ The following Table reports selected German business cycles characteristics and it is shown that the Dunlop-Tarshis puzzle is present here too.

\begin{tabular}{|l|l|l|l|l|}
\hline \multicolumn{4}{|l|}{$\begin{array}{l}\text { Selected German Business Cycle } \\
\text { Statistics, Quarterly, 1970:I-1994:IV }\end{array}$} \\
\hline \hline Variable & $\begin{array}{l}\text { Relative } \\
\text { volatility }\end{array}$ & \multicolumn{2}{|l|}{$\begin{array}{l}\text { Dynamic correlation } \\
\text { of } A(t) \text { and } B(t-j) \\
\text { with } j=\end{array}$} \\
\hline \hline I & $B$ & $\sigma_{B} / \sigma_{A}$ & 0 & -1 \\
\hline \hline Y & - & $1.50^{*}$ & 1.00 & 0.86 \\
\hline Y & C & 0.87 & 0.75 & 0.69 \\
\hline Y & I & 2.57 & 0.86 & 0.85 \\
\hline Y & L & 0.69 & 0.75 & 0.90 \\
\hline L & P & 1.02 & 0.12 & -0.03 \\
\hline
\end{tabular}

Basic source of data: OECD. Quarterly data are for 1970:I-1994:IV, employment se-

\footnotetext{
${ }^{22}$ See Tarshis (1939) and Dunlop (1938).

${ }^{23}$ This observation is at odds with Keynesian theory which views labor market fluctuations to take place along the labor demand curve. However, it is also at odds with the classical view that these fluctuations can be explained as movements along the labor supply curve (as the result of shifts of the labor demand schedule).
} 
ries for 1970:I-1993:IV. The variables are defined as follows. Y-Gross Domestic Output, $C$-Consumption expenditures, $I$-Investment expenditures, $L$-Total Employment. All variables have been logged and detrended with the Hodrick-Prescott filter. ${ }^{*}$ indicates that the number is the simple, not relative, standard deviation times 100 .

Table 7 demonstrates that the German business cycle exhibits similar characteristics to those of the U.S. business cycle. The only major difference is the behavior of productivity which is marginally more volatile than employment in the German economy. Also, the correlation of productivity and employment is positive, however, still very close to zero.

The process of firms' entry and exit takes on an important role in the present model. I shall present some evidence on the behavior of firms' entry and exit decisions over the business cycle. The procyclical behavior of net business formation is well documented for the U.S. economy (see for example Audretsch and Acs, 1991). The following Table reports the contemporaneous correlation of German GDP and three measures of firms' participation rate. Deviations from the trend of Hodrick-Prescott filtered time series are reported.

\begin{tabular}{|l|l|}
\hline \multicolumn{2}{|c|}{ Table 8 } \\
\hline \hline Variable & correlation with GDP \\
\hline \hline Limited companies & 0.35 \\
\hline Stock companies & 0.60 \\
\hline Insolvencies & -0.79 \\
\hline
\end{tabular}

Annual data was logged and Hodrick-Prescott filtered. The variables are the following. Number of firms: limited companies (GmbHs), stock companies (AGs) and insolvencies. Basic source of data: Statistisches Bundesamt.

Table 8 reports procyclical behavior of the number of firms in the German economy. In addition, market exit (as measured by insolvency) appears to be present mainly at business cycle downturns.

\subsection{Model moments}

Sunspot equilibria are defined as rational expectations equilibria in which cyclical behavior arises in response to arbitrary random events that do not 
have an effect on the fundamental equilibrium conditions of the economy. Once the sequence of sunspots is generated, the law of motion of the economy, which includes technology shocks, is given by

$$
\left[\begin{array}{c}
\hat{p}_{t+1} \\
\hat{K}_{t+1} \\
\hat{Z}_{t+1}
\end{array}\right]=J\left[\begin{array}{c}
\hat{p}_{t} \\
\hat{K}_{t} \\
\hat{Z}_{t}
\end{array}\right]+\left[\begin{array}{c}
u_{t+1} \\
0 \\
z_{t+1}
\end{array}\right]
$$

In the remainder of this section I will report the sample moments of my model for various calibrations. The model statistics are computed by applying the formulae developed by Uhlig (1995) on the matrix-valued law of motion (44). ${ }^{24}$ I will first specify a baseline calibration which will not be altered unless otherwise noted:

\begin{tabular}{|l|l|l|l|l|l|}
\hline \multicolumn{5}{|c|}{ Table 9: Parameters } \\
\hline \hline$\gamma$ & $\eta$ & $1 / \theta$ & $1 / v$ & $\beta$ & $\chi$ \\
\hline 1.00 & 1.33 & 1.36 & 1.03 & 0.99 & 0.00 \\
\hline
\end{tabular}

The value of $\chi$ implies that the intraperiod utility is equivalent to that in the Hansen-Rogerson model. The $v$ and $\theta$ calibrations follow the notion that significant increasing returns are only present in the investment goods sector. ${ }^{25}$ The specific value of $\theta$ is taken from Basu and Fernald (1996). ${ }^{26} \mathrm{I}$ will begin with a version of the model which is driven by a white noise animal spirits shock sequence only.

Table 10 considers the case of an economy which is driven by both animal spirits and technology shocks. The volatilities of both of the shocks is set at $\sigma_{z}=\sigma_{a}=0.0096 .^{27}$ Both shocks are uncorrelated. Furthermore I will

\footnotetext{
${ }^{24}$ See also the Appendix.

${ }^{25}$ See the Appendix for a formal derivation of a measure of scale economies in the present model.

${ }^{26}$ The value is at the upper end of their point estimates.

${ }^{27}$ McGrattan (1994) drives her version of a standard Real Business Cycle model with a technology shock of $\sigma_{z}=0.0096$. She traces her number from the familiar Solow decomposition by assuming constant returns to scale. No such theoretical counterpart exists to evaluate the variance of the animal spirits shock, however. Farmer and Guo (1994) choose the standard deviation of the animal spirits shock so that the model economy generates times series that match the volatility of U.S. output. As for the animal spirits model, this procedure is perfectly acceptable since no restrictions from the theory apply to the size of
} 
assume that technology is a highly persistent process: $\rho=0.974$ (see also McGrattan, 1994). Again the labor market parallels that of Hansen (1985).

\begin{tabular}{|l|l|l|l|l|}
\hline \multicolumn{5}{|c|}{ Table 10: Model Moments } \\
\hline \hline \multicolumn{2}{|l|}{ Variable } & $\begin{array}{l}\text { Relative } \\
\text { volatility }\end{array}$ & \multicolumn{2}{|l|}{$\begin{array}{l}\text { Dynamic correlation } \\
\text { of } A(t) \text { and } B(t-j) \\
\text { with } j=\end{array}$} \\
\hline$A$ & $B$ & $\sigma_{B} / \sigma_{A}$ & 0 & -1 \\
\hline \hline Y & - & $1.44^{*}$ & 1.00 & 0.72 \\
\hline Y & C & 0.91 & 0.71 & 0.51 \\
\hline Y & I & 2.78 & 0.73 & 0.53 \\
\hline Y & L & 0.73 & 0.47 & 0.35 \\
\hline Y & P & 0.91 & 0.71 & 0.51 \\
\hline Y & IS & 2.16 & 0.47 & 0.35 \\
\hline Y & N & 0.45 & 0.71 & 0.51 \\
\hline Y & M & 0.21 & 0.67 & 0.49 \\
\hline L & P & 1.26 & -0.28 & -0.20 \\
\hline D
\end{tabular}

Deviations from Hodrick-Prescott filtered trend of input variables. Variable definitions: $\mathrm{Y}=$ Output, $\mathrm{C}=$ Consumption expenditures, $\mathrm{I}=$ Investment, $\mathrm{L}=$ Hours, $\mathrm{P}=\mathrm{Y} / \mathrm{L}$, IS=investment expenditures share. * indicates that the number is the simple, not relative, standard deviation times 100 .

By evaluating the relative volatility of the variables, this first version of the model performs quite favorably: the relative standard deviations are all in the right order. However, consumption is almost as volatile as output in this version of the model. This is obviously at odds with data. Note that Gali's (1994) model displays a similar anomaly. ${ }^{28}$ The investment share is strongly procyclical, therefore confirming the intuition for indeterminacy that was given in the previous section, namely, that booms are the consequence of investment surges. ${ }^{29}$ Aggregate expenditures are procyclical. Also, hours and

the shock. See Woodford (1991) for this line of argument. However, I have chosen to use the same number as McGrattan for the animal spirits in the present model for comparision $\left(\sigma_{a}=0.0096\right)$.

${ }^{28}$ Real Business Cycle models typically underpredict the volatility of consumption. The King-Plosser-Rebelo baseline model, for example, strongly underpredicts a relative standard deviation of consumption (0.30 in King and Rebelo, 1993). Therefore the present model does not really perform any worse than most Real Business Cycle theories.

${ }^{29}$ Too much attention should not be focused on the exact absolute volatilities that are reported for the labor income share and the investment share in the model. The reported 
productivity are mildly negatively correlated. The prediction of the model is quite close to the value of -0.20 , as reported by McGrattan (1995) as well as by Baxter and King (1991). Table 10 also shows that all variables are strongly autocorrelated. Furthermore, hours are more volatile than productivity. The reason for the relativly low variability of the number of firms in the investment goods sector in relation to the consumption goods sector is the presence of strong increasing returns. A given change in (investment) demand can be met by a smaller response in inputs than the same demand change would require in the consumption goods sector.

Table 11 reports the same model driven again by two variables but it is now assumed that the standard deviation of the demand disturbances is twice the standard deviation of the technology shock: $\sigma_{a}=2 \sigma_{z}$.

\begin{tabular}{|l|l|l|l|l|}
\hline \multicolumn{3}{|c|}{ Table 11: Model Moments } \\
\hline \hline \multicolumn{2}{|l|}{ Variable } & $\begin{array}{l}\text { Relative } \\
\text { volatility }\end{array}$ & \multicolumn{2}{|l|}{$\begin{array}{l}\text { Dynamic correlation } \\
\text { of } A(t) \text { and } B(t-j) \\
\text { with } j=\end{array}$} \\
\hline Y & - & $1.06^{*}$ & 1.00 & 0.73 \\
\hline Y & C & 0.98 & 0.46 & 0.33 \\
\hline Y & I & 3.70 & 0.71 & 0.52 \\
\hline Y & L & 0.82 & 0.53 & 0.39 \\
\hline Y & P & 0.89 & 0.63 & 0.45 \\
\hline Y & IS & 3.08 & 0.53 & 0.39 \\
\hline Y & N & 0.48 & 0.46 & 0.33 \\
\hline Y & M & 0.28 & 0.67 & 0.49 \\
\hline L & P & 1.08 & -0.32 & -0.24 \\
\hline D & & & & \\
\hline
\end{tabular}

Deviations from Hodrick-Prescott filtered trend of input variables. Variable definitions: $\mathrm{Y}=$ Output, $\mathrm{C}=$ Consumption expenditures, I=Investment, $\mathrm{L}=$ Hours, $\mathrm{P}=\mathrm{Y} / \mathrm{L}$, IS=investment expenditures share. * indicates that the number is the simple, not relative, standard deviation times 100 .

Most visible in Table 11 is the effect on the labor market. If more weight is placed on animal spirits, the volatility of hours increases and it is the same as in U.S. data. The remaining variables are also close to U.S. business cycle characteristics.

model moments are the statistics of the logarithm of the respective shares, whereas in Table 6 logarithms were not taken. 
Table 12 reports the statistics of a version of the model that assumes significantly lower scale economies in the investment goods sector. In particular, I assume $1 / \theta=1.23$ and $\eta=1.20$. The model is driven by both shocks (equal variance) and $\chi=0$.

\begin{tabular}{|l|l|l|l|l|}
\hline \multicolumn{2}{|c|}{ Table 12: Model Moments } \\
\hline \hline \multicolumn{2}{|l|}{ Variable } & $\begin{array}{l}\text { Relative } \\
\text { volatility }\end{array}$ & \multicolumn{2}{|l|}{$\begin{array}{l}\text { Dynamic correlation } \\
\text { of } A(t) \text { and } B(t-j) \\
\text { with } j=\end{array}$} \\
\hline Y & - & $1.72^{*}$ & 1.00 & 0.74 \\
\hline Y & C & 0.82 & 0.35 & 0.24 \\
\hline Y & I & 3.88 & 0.80 & 0.51 \\
\hline Y & L & 1.05 & 0.68 & 0.41 \\
\hline Y & P & 0.82 & 0.35 & 0.24 \\
\hline Y & IS & 3.13 & 0.68 & 0.41 \\
\hline Y & N & 0.41 & 0.35 & 0.24 \\
\hline Y & M & 0.45 & 0.78 & 0.59 \\
\hline L & P & 0.78 & -0.45 & -0.34 \\
\hline Dev
\end{tabular}

Deviations from Hodrick-Prescott filtered trend of input variables. Variable definitions: $\mathrm{Y}=$ Output, $\mathrm{C}=$ Consumption expenditures, $\mathrm{I}=$ Investment, $\mathrm{L}=$ Hours, $\mathrm{P}=\mathrm{Y} / \mathrm{L}$, IS=investment expenditures share. * indicates that the number is the simple, not relative, standard deviation times 100 .

Table 12 shows that the reported model statistics are not dependent on large increasing returns in the investment goods sector. Moreover, for some variables like consumption, the model performs even better than before. Note that in the last version the volatility of $M$ exceeded the one of $N$. The reason for this is the following: for a given change in the expenditures on investment goods, the inputs (number of firms) must be adjusted to a greater extent than for higher scale economies. If scale economies are increased as described, the model features one further important prediction: the absolute volatility of output (and the other variables) is almost the same as in U.S. data. The model can account for almost all observed fluctuations.

Finally, Table 13 considers a version of the model for the case of constant marginal costs in both sectors. The variance of the technology shocks is twice the variance of the animal spirits shocks and $\chi=0$. 


\begin{tabular}{|l|l|l|l|l|}
\hline \multicolumn{3}{|c|}{ Table 13: Model Moments } \\
\hline \hline \multicolumn{2}{|l|}{ Variable } & $\begin{array}{l}\text { Relative } \\
\text { volatility }\end{array}$ & \multicolumn{2}{|l|}{$\begin{array}{l}\text { Dynamic correlation } \\
\text { of } A(t) \text { and } B(t-j) \\
\text { with } j=\end{array}$} \\
\hline Y & - & $1.23^{*}$ & 1.00 & 0.69 \\
\hline Y & C & 0.93 & 0.23 & 0.11 \\
\hline Y & I & 4.39 & 0.77 & 0.48 \\
\hline Y & L & 1.20 & 0.68 & 0.51 \\
\hline Y & P & 0.93 & 0.23 & 0.11 \\
\hline Y & IS & 3.67 & 0.68 & 0.48 \\
\hline Y & N & 0.45 & 0.23 & 0.11 \\
\hline Y & M & 0.22 & 0.68 & 0.51 \\
\hline L & P & 0.77 & -0.51 & -0.37 \\
\hline Dev
\end{tabular}

Deviations from Hodrick-Prescott filtered trend of input variables. Variable definitions: $\mathrm{Y}=$ Output, $\mathrm{C}=$ Consumption expenditures, I=Investment, $\mathrm{L}=$ Hours, $\mathrm{P}=\mathrm{Y} / \mathrm{L}$, IS=investment expenditures share. * indicates that the number is the simple, not relative, standard deviation times 100 .

Table 13 demonstrates that without a downward sloping marginal costs schedule in the investment goods sector, the model performs less successfully. The propagation mechanism worsens and labor input becomes too volatile.

\section{Conclusion}

In this paper I have developed a two-sector growth model which allows indeterminacy to occur at relatively mild degrees of increasing returns. Furthermore, it is shown that it is sufficient that these economies of scale are present in only one sector of the economy. This feature of the model, therefore, builds on evidence that was recently reported by Basu and Fernald (1996).

The model is also able to solve some puzzles of business cycle research which standard Real Business Cycle models have not been able to. Namely, the introduction of animal spirits in my model allows the generation of a low negative contemporaneous correlation of hours and productivity. Furthermore the investment share is procylical over the business cycle. Considering more standard measures of the business cycle such as the relative volatility of aggregate variables and comovements, my model performs equally as well as existing Real Business Cycle models. Especially concerning the model's 
predictions on the labor market, my model adequately produces a realistic relative volatility of hours without having to rely on the indivisible labor construct as in Hansen (1985). 


\section{References}

[1] Audretsch, David B. and Z. J. Acs (1991): "New-Firm Startups, Technology and Macroeconomic Fluctuations", WZB, Discussion Paper, \# 91-17.

[2] Basu, Susanto (1995): "Procyclical Productivity: Increasing Returns or Cyclical Utilization?", NBER, Working Paper \# 5336, and Quarterly Journal of Economics, (forthcoming).

[3] Basu, Susanto and John G. Fernald (1996): "Returns to Scale in U.S. Production: Estimates and Implications", Board of Governors of the Federal Reserve System, International Finance Discussion Papers \# 546.

[4] Basu, Susanto and John G. Fernald (1995): "Aggregate Productivity and the Productivity of Aggregates", Board of Governors of the Federal Reserve System, International Finance Discussion Papers \# 532.

[5] Basu, Susanto and John G. Fernald (1995): "Are Apparent Productivity Spillovers a Figment of Specification Error?", Journal of Monetary Economics, 36, 165-188.

[6] Basu, Susanto and John G. Fernald (1994): "Constant Returns and Small Markups in U.S. Manufacturing", Board of Governors of the Federal Reserve System, International Finance Discussion Papers \# 483.

[7] Baxter, Mariannne Robert G. King (1991): "Productive Externalities and Business Cycles", Institute for Empirical Macroecomics, Federal Reserve Bank of Minneapolis Discussion Paper \# 53.

[8] Benhabib, Jess and Roger E. A. Farmer (1994): "Indeterminacy, and Increasing Returns", Journal of Economic Theory, 63, 19-41.

[9] Benhabib, Jess and Roger E. A. Farmer (1996): "Indeterminacy, and Sector Specific Externalities", Journal of Monetary Economics, 37, 421-443.

[10] Boldrin, Michele, Lawrence J. Christiano and Jonas D. M. Fisher (1995): "Asset Pricing Lessons for Modeling Business Cycles", Federal Reserve Bank of Minneapolis, Working Paper \# 560.

[11] Burda, Michael C. (1985): "New Evidence on Real Wage-Employment Correlations from U.S. Manufacturing Data", Economics Letters, 18, 283-285.

[12] Christiano, Lawrence J. and Martin Eichenbaum (1992): "Current Real Business Cycle Theories and Aggregate Labor-Market Fluctuations", American Economic Review, 82, 430-450.

[13] Christiano, Lawrence J. and Jonas D. M. Fisher (1995): "Tobin's q and Asset Returns: Implications for Business Cycle Analysis", Federal Reserve Bank of Minneapolis Staff Report \# 200.

[14] Christiano, Lawrence J. and Richard M. Todd (1996): "Time to Plan and Aggregate Fluctations", Federal Reserve Bank of Minneapolis Quarterly Review, 20, 14-27. 
[15] Dunlop, John (1938): "The Movement of Real and Money Wage Rates", Economic Journal, 48, 413-434.

[16] Farmer, Roger E.A. (1993): The Macroeconomics of Self-Fulflling Prophecies, MIT Press, Cambridge.

[17] Farmer, Roger E. A. and Jang Ting Guo (1994): "Real Business Cycles and the Animal Spirits Hypothesis", Journal of Economic Theory, 63, 42-72.

[18] Gali, Jordi (1994): "Monopolistic Competition, Business Cycles and the Composition of Aggregate Demand", Journal of Economic Theory, 63, 73-96.

[19] Gali, Jordi (1995): "Non-Walrasian Unemployment Fluctuations", NBER Working Paper \# 5337.

[20] Gerlach, Stefan and Frank Smets (1995): "The Monetary Transmission Mechanism", CEPR Discussion Paper \# 219.

[21] Hansen, Gary D. (1985): "Indivisible Labor and the Business Cycle", Journal of Monetary Economics, 16, 309-328.

[22] King, Robert G., Charles I. Plosser and Sergio T. Rebelo (1988): "Production Growth and Business Cycles I: The Basic Neoclassical Model", Journal of Monetary Economics, 21, 195-232.

[23] King, Robert G. and Sergio T. Rebelo (1989): "Low Frequency Filtering and Real Business Cycles", Rochester Center for Economic Research Working Paper \# 205.

[24] Kydland, Finn E. and Edward C. Prescott (1990): "Business Cycles: Real Facts and a Monetary Myth", Federal Reserve Bank of Minneapolis Quarterly Review, 14, $3-18$.

[25] Kydland, Finn E. and Edward C. Prescott (1982): "Time To Built and Aggregate Fluctuations", Econometrica, 50, 1345-1370.

[26] McGrattan, Ellen R. (1994): "A Progress Report on Business Cycle Models", Federal Reserve Bank of Minneapolis Quarterly Review, 18, 2-16.

[27] Morrison, Catherine (1990): "Market Power, Economic Profitability and Productivity Growth Measurement: An Integrated Structual Approach", NBER Working Paper \# 3355.

[28] Rogerson, Richard (1987): "Indivisible Labor, Lotteries and Equilibrium", Journal of Monetary Economics, 21, 3-16.

[29] Rotemberg, Julio and Michael Woodford (1991): "Markups and the Business Cycle", in NBER Macroeconomics Annual, 6, 63-129.

[30] Schmitt-Grohe, Stefanie (1995): "Comparing Four Models of Aggregate Fluctuations Due to Self-Fulfilling Expectations", Federal Reserve Board Finance and Economics Discussion Papers \# 95-17. 
[31] Shell, Karl (1967): "Optimal Programs of Capital Accumulation for an Economy in which there is Exogenous Technical Change", in Karl Shell (ed.): Essays on the Theory of Optimal Economic Growth, MIT Press, Cambridge, 1-16.

[32] Takayama, Akira (1994): Analytical Methods in Economics, Harvester Wheatsheaf, New York.

[33] Tarshis, Lois (1939): "Changes in Real and Money Wage Rates", Economic Journal, $49,150-154$.

[34] Uhlig, Harald (1995): "A Toolkit for Analyzing Nonlinear Dynamic Stochastic Models Easily", Tilburg University CentER Discussion Paper \# 9597.

[35] Woodford, Michael (1986): "Stationary Sunspot Equilibria: The Case of Small Fluctuations Around a Deterministic Steady State", University of Chicago, unpublished.

[36] Woodford, Michael (1991): "Self-Fulfilling Expectations and Fluctuations in Aggregate Demand", in N. Gregory Mankiw and David Romer (eds.): New Keynesian Macroeconomics, MIT Press, Cambridge. 


\section{Appendix}

\subsection{The measure of returns to scale}

Suppose that the production function of a firm is given by ${ }^{30}$

$$
Y_{t}=F\left(K_{t}, L_{t}\right)-\Gamma \text {. }
$$

$\Gamma$ denotes overhead costs. $F$ is homogenous of degree $\gamma$. Following the assumption that is made in the text, the functional form of $F\left(K_{t}, L_{t}\right)$ is Cobb-Douglas with $F\left(K_{t}, L_{t}\right)=K_{t}^{\alpha \gamma} L_{t}^{(1-\alpha) \gamma}$. Profits for the firm are given by

$$
\Pi_{t}=p_{t} Y_{t}-w_{t} L_{t}-q_{t} K_{t}
$$

Denote the mark up over marginal costs by $\mu_{t}$, then the last equation implies that

$$
\Pi_{t}=p_{t} Y_{t}-\frac{\gamma}{\mu_{t}} p_{t} F\left(K_{t}, L_{t}\right)
$$

holds. ${ }^{31}$ It is assumed in the text that profits are forced to zero by market entry and exit. This yields

$$
0=Y_{t}-\frac{\gamma}{\mu_{t}}\left(Y_{t}+\Gamma\right)
$$

and

$$
Y_{t}\left(\frac{\mu_{t}}{\gamma}-1\right)=\Gamma
$$

which restricts $\mu_{t} \geq \gamma$. A useful measure of returns to scale is the ratio of average to marginal costs (see for example Takayama, 1994). Denote returns

\footnotetext{
${ }^{30}$ All variables have the same definition as in the main text unless otherwise noted.

${ }^{31}$ This equation uses the fact that

$$
\mu_{t} w_{t}=p_{t} F_{L}\left(K_{t}, L_{t}\right)
$$
}

and

$$
\mu_{t} q_{t}=p_{t} F_{K}\left(K_{t}, L_{t}\right) .
$$


to scale by $\Phi$. Profit maximization implies (together with Cobb-Douglas technology)

$$
\Phi=\frac{A q_{t}^{\alpha} w_{t}^{1-\alpha}\left(Y_{t}+\Gamma\right)^{\frac{1}{\gamma}}}{Y_{t}} \frac{\gamma}{A q_{t}^{\alpha} w_{t}^{1-\alpha}\left(Y_{t}+\Gamma\right)^{\frac{1}{\gamma}-1}}=\gamma \frac{Y_{t}+\Gamma}{Y_{t}}
$$

where $A$ is a constant. ${ }^{32}$ Using (50) the last equation reduces to $\Phi=\mu_{t}$. Therefore, increasing returns are, given the assumptions made in the text, equal to the markup. ${ }^{33}$

This can be interpreted as follows: Assume that $\mu_{t} \rightarrow 1$. This means that the market structure approaches perfect competition. Average costs equal marginal costs and the firm produces at minimum average cost. This situation cannot be consistent with positive overhead, however. As $\mu$ rises, firms gain market power over their product. Using the zero profit condition the size of each firm's output (with zero profits) can be determined. In addition, each firm now produces with increasing returns to scale. It is implicit in equation (50) that the measure of increasing returns to scale is exactly equal to the mark up. The measure is independent of the degree of homogeneity of $F$ (and therefore $\gamma$ ). $\gamma$ determines the slope of the marginal costs schedule only.

\subsection{Applying the Hodrick-Prescott filter without si- mulating the model}

To judge the model's success in replicating actual business cycle behavior, I will derive the relevant model statistics. This will be done by applying (what is called in economics) the Hodrick-Prescott filter.

Here I follow Uhlig (1995) who does not simulate the model to derive the population moments but rather chooses the linearized version of the model directly by the use of frequency domain techniques. Consider the first order

\footnotetext{
${ }^{32}$ Reminder: the cost function is given by $A q_{t}^{\alpha} w_{t}^{1-\alpha}\left(Y_{t}+\Gamma\right)^{\frac{1}{\gamma}}$.

${ }^{33}$ Note that this measure of returns to scale is not dependent on entry and exit of firms per se. Actually, this local measure would be the same if one would assume that profits average to zero as in Hornstein (1993) (combined with a constant number of firms).
} 
vector autoregressive process (given by equation 44)

$$
s_{t+1} \equiv\left[\begin{array}{c}
\hat{p}_{t+1} \\
\hat{K}_{t+1} \\
\hat{Z}_{t+1}
\end{array}\right]=J\left[\begin{array}{c}
\hat{p}_{t} \\
\hat{K}_{t} \\
\hat{Z}_{t}
\end{array}\right]+v_{t+1} \equiv J s_{t}+v_{t+1}
$$

where $v_{t+1}$ respresents the vector of innovations. $E\left[v_{t+1} \mid I_{t}\right]=0$ and

$$
E\left[v_{t} v_{t+\tau}\right]=\left\{\begin{array}{l}
\Sigma \text { for } t=\tau \\
0 \text { otherwise. }
\end{array}\right.
$$

The population spectrum of (55) is given by

$$
S(\omega)=(2 \pi)^{-1}\left[I_{3}-J e^{-i \omega}\right]^{-1} \Sigma\left[I_{3}-J^{\prime} e^{i \omega}\right]^{-1}
$$

where $I_{3}$ is a $3 \times 3$ identity matrix. Since I am interested in the spectral density of the Hodrick-Prescott filtered version of the model, I apply the HP-transfer function (see King and Rebelo, 1994) to obtain

$$
S(\omega)^{H P}=\left[\frac{4 \cdot \lambda(1-\cos (\omega))^{2}}{1+4 \cdot \lambda(1-\cos (\omega))^{2}}\right]^{2} S(\omega) .
$$

The parameter $\lambda$ penalizes variations in the growth component. It is recommended to set $\lambda=1600$ for quarterly data. The first term in (53), the HP-transfer function, is particularly easy to interpret. It places zero weight on the zero frequency, that is $S(0)^{H P}=0$. On the other hand it places close to unit weight on high frequencies:

$$
S(\pi)^{H P}=\left(\frac{16 \cdot \lambda}{1+16 \cdot \lambda}\right)^{2} S(\pi) \approx S(\pi) .
$$

The spectral density of all variables of the vector $\hat{\Omega}_{t}=\Pi s_{t}$ is given in matrix notation as

$$
\bar{S}(\omega)^{H P}=\left[\frac{4 \cdot 1600(1-\cos (\omega))^{2}}{1+4 \cdot 1600(1-\cos (\omega))^{2}}\right]^{2} \Pi S(\omega) \Pi^{\prime}
$$

and I finally obtain the $k$ th autocovariance matrix of the elements of $s$ :

$$
\int_{-\pi}^{\pi} \bar{S}(\omega)^{H P} e^{i \omega k} d \omega
$$

For $k=0$ the variances and covariances are obtained. 